\title{
Correction to: Ethology and Behavioral Ecology of Odontocetes
}

\author{
Bernd Würsig
}

\section{Correction to:}

B. Würsig (ed.), Ethology and Behavioral Ecology of Odontocetes, Ethology and Behavioral Ecology of Marine Mammals, https://doi.org/10.1007/978-3-030-16663-2

The book was inadvertently published with the incorrect captions for Fig. 9.1 in Chap. 9 and for Fig. 21.8 in Chap. 21, which has been updated as below:

Fig. 9.1:

"Dolphins of the eastern tropical Pacific (ETP). Top: Central American spinner dolphin, "whitebelly" spinner dolphin; Middle: striped dolphin, coastal pantropical spotted dolphin; Bottom: offshore pantropical spotted dolphin, short-beaked common dolphin. Latin names are in Appendix 1. The species have overlapping ranges but distinct habitat preferences and different school sizes, social structure, and behavior (see text). Photo credit: Southwest Fisheries Science Center, NOAA Fisheries"

Fig. 21.8:

"Harbor porpoise mating at the surface. The female in front lifts her flukes high out of the water in response to the male's approach. The penis is barely visible near the genital area. Note that the male approach on the left side of the female is similar to all observations in Keener et al. (2018). Photo credit: Kurt Videbæk Jensen"

The corrections have been carried out in the chapters and the updated chapters have been approved by the authors.

The updated online versions of the chapters can be found at https://doi.org/10.1007/978-3-030-16663-2_9

https://doi.org/10.1007/978-3-030-16663-2_21 